\title{
FAKTOR YANG BERHUBUNGAN DENGAN KEPATUHAN PENGUNJUNG TERHADAP KAWASAN TANPA ROKOK DI RUMAH SAKIT UMUM DAERAH
}

\author{
Syamsul Naiem ${ }^{1}$, Muh.Anwar ${ }^{2}$ \\ ${ }^{1}$ Kampus Universitas Al Asyariah Mandar, Fakultas Kesehatan Masyarakat. \\ Jl. Budi Utomo No.2 Manding, Kecamatan Polewali, Kabupaten Polewali Mandar, Provinsi Sulawesi \\ Barat, Indonesia \\ E-mail: Syamsulnaiem2019@gmail.com.
}

\begin{abstract}
Abstrack
The cigarette is a national problem and still be prioritize the efforts to penanggulangannya because cigarettes on various aspects of problem in life, Namely the economic aspect, Political and health. The purpose of other factors in this research to that which, influences compliance to visitors without cigarettes in the district general hospital kabupaten polewali mandar. The kind of research used namely the observational with the design cross sectional .Random sample taken with uses the method (random sampling). At 40 respondents.The data collection was done by using instrument in the form of research and that it is processed using spss program of the questionnaire was 21. The result showed no connection between the influence of knowledge by compliance visitors in areas without cigarettes visitors at a public hospital by the value $p=0.019$, There is a compliance with the visitors in areas without cigarettes visitors in the general hospital $p=0.019$, And there was a correlation between media his compliance visitors in areas without cigarettes in value $p=0.385$. Advice of research, namely to improve health in the hospital district polewali mandar to danger smoking should be made the elucidation through the establishment of a team promoting the health of the dangers cigarettes
\end{abstract}

\begin{abstract}
ABSTRAK
Masalah rokok masih menjadi masalah nasional dan masih menjadi prioritas dalam upaya penanggulangannya karena rokok menyangkut berbagai aspek permasalahan dalam kehidupan, yaitu aspek ekonomi, sosial politik dan kesehatan. Tujuan dalam penelitian ini untuk melihat faktor apa yang mempengaruhi kepatuhan pengunjung terhadap kawasan tanpa rokok di Rumah Sakit Umum Daerah Kabupaten Polewali Mandar. Jenis penelitian yang digunakan yaitu observasional dengan desain cross sectional. Sampel diambil dengan menggunakan metode acak (random sampling) pada 40 responden. Pengumpulan data dilakukan dengan menggunakan instrument penelitian berupa kuisioner dan diolah menggunakan program SPSS 21. Hasil penelitian menunjukkan ada hubungan antara pengaruh pengetahuan dengan kepatuhan pengunjung terhadap kawasan tanpa rokok pengunjung di Rumah Sakit Umum dengan nilai $p=0.019$, ada hubungan sikap dengan kepatuhan pengunjung terhadap kawasan tanpa rokok pengunjung di Rumah Sakit Umum dengan nilai $\mathrm{p}=0.019$, dan tidak ada hubungan antara media dengan kepatuhan pengunjung terhadap kawasan tanpa rokok dengan nilai $\mathrm{p}=0.385$. Saran dari peneliti, yaitu dalam upaya meningkatkan kesehatan di lingkungan Rumah Sakit Kabupaten Polewali Mandar terhadap bahaya merokok sebaiknya di buat program penyuluhan melalui pembentukan tim promosi kesehatan mengenai bahaya rokok.
\end{abstract}

Kata kunci : Pengetahuan, sikap, kawasan tanpa rokok

\section{PENDAHULUAN}

Saat ini rokok masih saja menjadi salah satu produk yang tingkat konsumsinya relatif tinggi di masyarakat. Masalah rokok masih menjadi masalah nasional dan masih saja diprioritaskan upaya penanggulangannya karena rokok menyangkut berbagai aspek permasalahan dalam kehidupan,yaitu aspek ekonomi, sosial politik dan 
terutama aspek kesehatan (Kesehatan \& Indonesia, 2011).

Asap rokok yang dikonsumsi menghasilkan zat yang sangat berbahaya bagi kesehatan si perokok sendiri sebagai perokok aktif, maupun orang lain yang ada disekitarnya sebagai perokok pasif. Pada dasarnya asap rokok terdiri dari asap utama yang mengandung $25 \%$ kadar berbahaya dan asap sampingan yang mengandung $75 \%$ kadar berbahaya. Perokok pasif menghisap $75 \%$ bahan berbahaya ditambah separuh dari asap yang dihembuskan.

Dari sebatang rokok mengandung 4000 bahan kimia beracun dan tidak kurang dari 69 diantaranya bersifat karsinogenik. Sehingga rokok dan lingkungan yang tercemar asap rokok dapat membahayakan kesehatan. Kandungan bahan kimia tersebut dapat menyebabkan berbagai penyakit tidak menular seperti jantung dan gangguan pembuluh darah, stroke, kanker paru, dan kanker mulut. Selain itu, rokok juga dapat menyebabkan penurunan kesuburan, pertumbuhanjanin baik fisik maupun IQ (Intelegent Quotient) yang melambat, gangguan imunitas bayi, dan peningkatan kematian (Aditama, 2006).

WHO, 2008. Data epidemik tembakau didunia menurut World Health Organizatio menunjukan 1 kematian karena merokok di seluruh dunia terjadi tiap 6 detik. Kematian karena merokok pada tahun 2005 tercatat sebanyak 5,4 juta jiwa dan selama abad ke 20 telah terjadi sebanyak 100 juta kematian akibat merokok. Jika hal ini terus dibiarkan maka terjadi 8 juta kematian pada tahun 2030 dan dapat diperkirakan akan terjadi kematian sebanyak 1 milyar jiwa akibat merokok selama abad ke 21. Pada tahun 2030 diproyeksikan $80 \%$ kematian terkait merokok terjadi di negara berkembang.

Indonesia merupakan salah satu negara konsumen tembakau terbesar didunia.Pada tahun 2005 Indonesia menempati peringkat kelima konsumen rokok terbesar setelah China, Amerika Serikat, Rusia dan Jepang. Pada tahun 2008 Badan Kesehatan Dunia WHO telah menetapkan Indonesia sebagai negara terbesar ketiga sebagai pengguna rokok, setelah China, dan India.

\section{Badan Kesehatan Dunia (WHO)} memperkirakan setengah juta kematian didunia dikarenakan paparan asap rokok orang lain (AROL). Pada tahun yang sama, riset kesehatan dasar menyebutkan bahwa penduduk berumur lebih dari 10 tahun yang merokok sebesar 29,2 persen, dan angka tersebut meningkat sebesar 34,7 persen pada tahun 2010 untuk kelompok umur di atas 15 tahun (Riskesdas, 2010).

Sesuai dengan peraturan Daerah Kabupaten Polewali Mandar No 4 Tahun 2015 tentang Kawasan tanpa rokok bahwa untuk melaksanakan ketentuan dalam Pasal 115 ayat (2) UndangUndang Nomor 36 Tahun 2009 tentang Kesehatan, ketentuan dalam Pasal 52 Peraturan Pemerintah Nomor 109 Tahun 2012 tentang pengamanan bahan yang mengandung zat adiktif berupa produk tembakau bagi kesehatan, dan ketentuan dalam Pasal 6 ayat (1) Peraturan Bersama Menteri Kesehatan dan Menteri Dalam Negeri Nomor 188/MENKES/PB/I/2011 dan Nomor 7 Tahun 2011 tentang pedoman pelaksanaan kawasan tanpa rokok. manusia merupakan makhluk sosial yang memebutuhkan peranan manusia lainnya untuk memenuhi kebutuhannya. Maka dari itu manusia perlu melakukan interaksi dengan manusia lain 
komunikasi merupakan modal utama manusia untuk melakukan interaksi sosial dengan manusia lainnya guna memenuhi kebutuhan hidup mereka Komunikasi dalam bentuk paling sederhana adalah transmisi pesan dari suatu sumber ke penerima. (StanleyJ.Baran 2012)

Dapat kita lihat bahwa didinding-dinding di sekitar lingkungan RSUD Kabupaten Polewali Mandar sudah terpasang larangan untuk merokok. Namun dalam kenyataannya, Banyak sekali terlihat perilaku pengunjung di lingkungan rumah sakit sehari-harinya tidak menunjukkan adanya kepatuhan terhadap peraturan tersebut.

Petugas RSUD Rumah Sakit Umum Daerah sering mendapati pengunjung yang merokok dilingkungan RSUD Kabupaten Polewali Mandar namun beberapa dari mereka tidak menghiraukan jika ditegur,mereka mematikan rokok pada saat ditegur akan tetapi setelah petugas meninggalkan mereka, mereka kembali membakar rokok tersebut.

Pengetahuan dan sikap terhadap bahaya merokok dan adanya peraturan Kawasan Tanpa Rokok ini perlu diketahui karena akan berpengaruh terhadap keberhasilan jalannya kebijakan tersebut. Pengetahuan dapat diperoleh dengan berbagai cara diantaranya proses belajar terhadap suatu informasi yang diperoleh seseorang, pengalaman secara langsung maupun dari pengalaman orang lain serta proses pendidikan atau edukasi.

Dengan mengetahui seberapa besar pengetahuan orang tersebut terhadap bahaya merokok dan kawasan tanpa rokok,maka ini akan berpengaruh pada sikap pengujung terhadap Kebijakan Kawasan Tanpa Rokok (KTR) (Sumahandriyani,2015).
Bahan cetak seperti pamphlet, leaflet, dan poster merupakan program pendidikan kesehatan dengan jenis permintaan yang tinggi selama bertahun-tahun, tetapi banyak ditemui yang hanya menempati rak-rak dan papan buletin tanpa distribusi yang memadai ke sasaran.Permasalahan ini perlu diupayakan strategi promosi kesehatan.Salah satu strategi promosi kesehatan adalah pemberdayaan masyarakat.

Harapan dari upaya ini adanya partisipasi sasaran agar dapat mengatasi masalah dalam pengadaan media promosi kesehatan.Elemen penting dari promosi kesehatan adalah partisipasi aktif dari masyarakat.

Poster adalah salah satu jenis media promosi kesehatan yang dapat dikombinasikan pengetahuan dan sikap.Poster merupakan media grafis yang termasuk salah satu media visual, yang teknik pembuatannya unik sehingga dapat mengembangkan kreativitas seserang dalam membuat media kesehatan untuk mensosialisasikan bahaya rokok bagi kesehatan di lingkungan Rumah Sakit. (Mohamad, Prabandari, \& Priyanto, 2012).

Melihat hal tersebut, peneliti tertarik untuk meneliti tingkat pengetahuan dan sikap pengunjung rumah sakit tentang kawasan tanpa rokok serta bagaimana hubungan antara keduanya.Penelitian ini bertujuan untuk melihat apa saja faktor yang mempengaruhi kepatuhan pengunjung terhadap kawasan tanpa rokok di (RSUD) Kabupaten Polewali Mandar.

\section{METODE PENELITIAN}

Jenis penelitian yang digunakan dalam penelitian ini adalah observasional dengan desain cross sectional, Populasi penelitian di lakukan pada 
pengunjung yang berada di lingkungan RSUD Kabupaten Polewali Mandar, Sampel diambil dengan menggunakan metode acak (random sampling) sehingga setiap anggota populasi memiliki probabilitas yang sama untuk dipilih sebagai sampel dan populasi yang di ambil sebanyak 40 responden.

Pengumpulan data dalam penelitian ini dengan melakukan wawancara menggunakan kuesioner Instrumen yang digunakan dalam penelitian ini adalah lembar kuesioner. Data sekunder diperoleh dari data dari RS dapat berupa buku, jurnal, laporan, makalah dan referensi lain yang memiliki hubungan dengan topik penelitian pertanyaan tertutup, dengan kata lain kuesioner tertutup adalah kuesioner yang berisikan daftar pertanyaan yang sudah disediakan jawaban oleh penelitian.

Analisis data menggunakan data primer berupa data deskriptif akan disajikan dalam bentuk tabel dan narasi. Kemudian data dianalisis yakni menggunakan uji Chi Square. Nilai derajat kemaknaan adalah apabila $p$ value $<0,05$, maka hipotesis nol akan ditolak. Analisis data akan menggunakan program SPSS (Statistical Package for

Social

Science).

\section{HASIL}

1. Karakteristik Responden

Tabel 1. Distribusi Frekuensi Responden Menurut Umur dan Pendidikan Pengunjung di Rumah Sakit Umum Daerah Polewali Mandar

\begin{tabular}{|c|c|c|c|}
\hline \multicolumn{2}{|c|}{ Karakteristik Responden } & $\mathrm{N}$ & $\%$ \\
\hline \multirow{5}{*}{ Umur } & $19-24$ & 10 & 25.0 \\
\hline & $25-29$ & 14 & 35.0 \\
\hline & $30-34$ & 8 & 20.0 \\
\hline & $35-39$ & 1 & 2.5 \\
\hline & $40-49$ & 7 & 17.3 \\
\hline \multirow{4}{*}{ Pendidikan } & $\mathrm{SD}$ & 4 & 10.0 \\
\hline & SMP & 8 & 20.0 \\
\hline & SMA & 23 & 57.5 \\
\hline & $\mathrm{S} 1$ & 5 & 12.5 \\
\hline \multicolumn{2}{|c|}{ Jumlah } & 40 & 100.0 \\
\hline
\end{tabular}

Sumber : Data primer 2019

Karakteristik umum dalam penelitian ini mencakup umur dan pendidikan responden pengunjungRumah Sakit. Berdasarkan tabel di bawah menunjukan bahwa jumlah responden pengunjung rumah sakit yang berumur 19-24 sebanyak 10 orang (25.0), 25-29 sebanyak 14 orang
(35.0), 30-34 sebanyak 8 orang (20.0), sedangkan 35-39 sebanyak 1 (2.5), dan yang berumur 40-49 sebanyak 7 Orang (17.3\%). Responden Yang berpendidikan SD sebanyak 4 orang (10.0), SMP sebanyak 8 orang (20.0) SMA sebanyak 23 orang (57.5)

S1 sebanyak 5 


\section{Analisis Bivariat Hubungan Antara Variabel}

Tabel 2. Hubungan Pengetahuan, Sikap, dan Media dengan Kepatuhan Pengunjung Terhadap Kawasan Tanpa Rokok Pengunjung di Rumah Sakit Umum Daerah Polewali Mandar

\begin{tabular}{|c|c|c|c|c|c|c|c|}
\hline \multirow{3}{*}{ Variabel } & \multicolumn{4}{|c|}{ Kepatuhan Pengunjung } & \multirow{2}{*}{\multicolumn{2}{|c|}{ Total }} & \multirow{3}{*}{$P$-Value } \\
\hline & \multicolumn{2}{|c|}{ Tidak Merokok } & \multicolumn{2}{|c|}{ Merokok } & & & \\
\hline & $\mathrm{n}$ & $\%$ & $\mathrm{n}$ & $\%$ & $\mathrm{n}$ & $\%$ & \\
\hline Pengetahuan & & & & & & & 0.19 \\
\hline Rendah & 4 & 22.2 & 14 & 77.8 & 18 & 100 & \\
\hline Tinggi & 13 & 59.1 & 9 & 40.9 & 22 & 100 & \\
\hline Sikap & & & & & & & 0,00 \\
\hline Baik & 2 & 10,5 & 17 & 89,5 & 19 & 100 & \\
\hline Buruk & 15 & 71,4 & 6 & 28,6 & 21 & 100 & \\
\hline Media & & & & & & & 3,85 \\
\hline Cukup & 9 & 50,0 & 9 & 50,0 & 18 & 100 & \\
\hline Kurang & 8 & 36,4 & 14 & 63,3 & 22 & 100 & \\
\hline
\end{tabular}

Sumber: Data primer 2019

Berdasarkan tabel 2 menunjukkan merokok sebanyak 6 orang $(28,6 \%)$. bahwa jumlah responden yang berdasarkan uji Chi-Square, P-value $=0.019$ berpengetahuan rendah sebanyak 18 orang, $\quad<\alpha$ 0,05 sehingga dapat di di simpulkan yang tidak merokok 4 orang $(22.2 \%)$ dan bahwa ada hubungan antara pengaruh yang merokok 14 orang $(77,8 \%)$ sedangkan pengetahuan terhadap kepatuhan kawasan jumlah responden yang berpengetahuan tinggi 22 orang, yang tidak merokok 13 tanpa rokok pengunjung di rumah sakit umum daerah Kabupaten Polewali Mandar, orang $(51,9 \%)$ dan yang merokok sebanyak 9 orang $(40,9 \%)$.

Berdasarkan uji Chi-Square, $\mathrm{P}$-value $=$ $0.019<\alpha \quad 0,05$ sehingga dapat di di simpulkan bahwa ada hubungan antara pengaruh pengetahuan terhadap kepatuhan kawasan tanpa rokok pengunjung dirumah sakit umum daerah Kabupaten Polewali Mandar. Jumlah keseluruhan responden sebanyak 19 orang, yang tidak merokok 2 orang $(10,5 \%)$ dan yang merokok 17 orang $(89,5 \%)$. Sedangkan jumlah responden yang bersikap buruk 21 orang $(28,6 \%)$, yang tidak merokok 15 orang $(71,4 \%)$ dan yang sebanyak 18 orang, pengaruh media yang cukup terhadap responden yang tidak merokok 9 orang $(50,0 \%)$ dan yang merokok 19 orang $(50,0 \%)$. Sedangkan jumlah pengaruh media terhadap responden kurang merokok 14 orang $(63,3 \%)$, yang tidak merokok 8 orang $(36,4 \%)$. berdasarkan uji Chi-Square, $\quad \mathrm{P}$-value $=0.019<\alpha \quad 0,05$ sehingga dapat disimpulkan bahwa ada hubungan antara pengaruh pengetahuan terhadap kepatuhan kawasan tanpa rokok pengunjung dirumah sakit umum daerah Kabupaten Polewali Mandar. 


\section{PEMBAHASAN}

1. Hubungan Pengetahuan dengan Kepatuhan Pengunjung Terhadap Kawasan Tanpa Rokok di Rumah Sakit Umum Daerah Kabupaten Polewali Mandar

Berdasarkan data yang diperoleh dari 40 pengunjung RSUD Kabupaten Polewali Mandar memiliki pengetahuan rendah, lebih sedikit dibandingkan kepatuhan responden yang merokok memiliki pengetahuan tinggi, dan berdasarkan uji Chi-Square, P-value = (0.019) di bawah dari $(0,05)$, sehingga dapat di simpulkan bahwa ada hubungan antara pengetahuan dengan kepatuhan kawasan tanpa rokok pengunjung, Bahwa pendidikan responden sebagian besar cukup baik (SMA - PT). Sehinga dapat disimpulkan bahwa pendidikan yang tinggi berpengaruh pada pengetahuan tentang bahaya rokok, Menurut Soekidjo Notoatmodjo(Notoatmodjo, 2003), pengetahuan seseorang dipengaruhi oleh berbagai faktor. Antara lain: umur, pendidikan, pekerjaan dan paparan informasi yang diperoleh dari masingmasing individu.

Hasil peneltian sejalan dengan Penelitian Rizkia Amalia 2012, tingkat pengetahuan dan sikap pengunjung di lingkingan RSUP Dr. Kariadi tentang kawasan tanpa rokok, terdapat kesamaan jumlah dan signifikan hubungan. Berdasarkan laporan penelitiannya menunjukkan 35 responden $(38,9 \%)$ merupakan responden berpengetahuan baik, sedangkan responden berpengetahuan cukup berjumlah 44 responden (48,9\%) dan responden berpengetahuan kurang sebesar 11 responden $(12,2 \%)$. Hasil dari analisis dengan menggunakan korelasi chi square pada penelitian ini menunjukkan bahwa terdapat hubungan yang signifikan antara tingkat pengetahuan yang baik pada responden dengan sikap patuh terhadap aturan kawasan tanpa rokok pada pengunjung pria di poliklinik penyakit dalam RSUP Dr.Kariadi

Hasil penelitan ini juga sejalan dengan hasil penelitian Robbaka (2013) Kepatuhan Mahasiswa terhadap Kawasan Tanpa Rokok Di Universitas Dian Nuswantoro Semarang 2013, Hubungan pengetahuan dengan kepatuhan terhadap Kawasan Tanpa Rokok pada mahasiswa UDINUS menggunakan uji Korelasi Rank Spearman didapatkan Pvalue sebesar 0,001 , berarti ada hubungan pengetahuan dengan kepatuhan terhadap Kawasan Tanpa Rokok, dimana responden yang mempunyai kepatuhan kurang baik terhadap KTR yang diketahui itu. Akhirnya rangsangan yakni obyek yang telah diketahui dan disadari sepenuhnya tersebut akan menimbulkan respon lebih 
jauh lagi, yaitu berupa tindakan (action) terhadap stimulus atau obyek.

\section{Hubungan Sikap dengan Kepatuhan} Pengunjung Terhadap Kawasan Tanpa Rokok Di Rumah Sakit Umum Daerah Kabupaten Polewali Manadar

Berdasarkan data penelitian tentang hubungan sikap terhadap kepatuhan pengunjung RSUD terhadap kawasan tanpa rokok, diperoleh hasil dari 40 responden menunjukkan bahwa sikap responden yang tidak merokok, memiliki sikap buruk lebih sedikit dibandingkan kepatuhan responden yang merokok memiliki sikap baik tinggi, dan berdasarkan uji Chi-Square, $\mathrm{P}-$ value $=$ $0.000<\alpha 0,05$, sehingga dapat di simpulkan bahwa ada hubungan antara hubungan sikap dengan kepatuhan terhadap kawasan tanpa rokok pengunjung di Rumah Sakit Umum Daerah Kabupaten Polewali Mandar. jika di bandingkan dengan penelitian Rizkia Amalia tahun 2012, tingkat pengetahuan dan sikap pengunjung di lingkingan RSUP Dr. Kariadi tentang kawasan tanpa rokok, sikap terbanyak pada jawaban pengunjung rumah sakit adalah menunjukkan patuh terhadap aturan kawasan tanpa rokok lebih banyak di banding sikap tidak patuh terhadap aturan kawasan tanpa rokok di rumah sakit.
3. Hubungan Media dengan Kepatuhan Pengunjung Terhadap Kawasan Tanpa Rokok Di Rumah Sakit Umum Daerah Kabupaten Polewali Mnadar

Berdasarkan data yang di dapat dari 40 responen bahwa pengaruh ketersediaan media terhadap responden yang tidak merokok $\geq$ dibandingkan dengan responden yang merokok $\mathrm{P}$ value $=0.385 \leq(0,05) \quad$ sehingga dapatdisimpulkan bahwa tidak ada hubungan antara pengaruh ketersediaan media terhadap kepatuhan kawasan tanpa rokok pengunjung di rumah sakit umum daerah Kabupaten Polewali Mandar, dari hasil penelitian mengenai pengaruh media dimana yang kurang lebih banyak dibanding yang cukup dimana ketersediaan media sehingga dapat di simpulkan bawha tidak ada hubungan antara pengaruh media terhadap larangan kawasan tanpa rokok di RSUD Kabupaten Polewali Mandar.

Terdapat perbedaan dengan penelitian (Hehir, Indig, Prosser, \& Archer, 2013)staf yang disurvei mendukung kebijakan tempat kerja bebas asap rokok; sebagian besar setuju bahwa perawatan pasien lebih mudah dan bahwa kebijakan itu tidak mengarah pada peningkatan perilaku merugikan pasien. Penerapan larangan merokok total dapat menghasilkan hasil kesehatan yang positif bagi pasien dan staf, dan dapat 
mempengaruhi beberapa staf untuk di rumah sakit umum daerah Kabupaten berhenti. Staf yang merokok memiliki Polewali Mandar. Dari hasil penelitian yang pengalaman kebijakan yang kurang positif didapat, maka terbentuk beberapa saran dari dan memerlukan dukungan tambahan dari peneliti, yaitu Dalam upaya meningkatkan beberapa pihak.

kesehatan di lingkungan rumah sakit,

Berbeda

dengan

Surahmawati, $\&$

(Habibi, Sompo, 2016)Berdasarkan hasil penelitian dapat disimpulkan bahwa implementasi Peraturan Daerah tentang Kawasan Tanpa Rokok (KTR) pada RSUD Haji dan Rumah Sakit Stella Maris pada dasarnya sudah diterapkan. Terdapat beberapa perubahan positif yang dirasakan baik oleh pegawai maupun oleh masyarakat seperti rumah sakit menjadi lebih rapi dan nyaman dengan berkurangnya polusi udara akibat paparan asap rokok, berkurangnya sampah yang berserakan akibat rokok.

\section{KESIMPULAN DAN SARAN}

Berdasarkan hasil penelitian tentang faktor yang mempengaruhi kepatuhan kawasan tanpa rokok pengunjung di rumah sakit umum daerah Kabupaten Polewali Mandar menunjukkan bahwa ada hubungan antara pengaruh sikap terhadap kepatuhan kawasan tanpa rokok pengunjung di rumah sakit umum daerah Kabupaten Polewali Mandar dan tidak ada hubungan antara pengaruh ketersediaan media terhadap kepatuhan kawasan tanpa rokok pengunjung khususnya RSUD Kabupaten Polewali Mandar terhadap bahaya merokok maupun bahaya dari asap rokok sebaiknya di buat program penyuluhan mengenai bahaya merokok, agar para pengunjung dapat menyadari bahwa rokok dapat menurunkan kualitas kesehatan diri dan orang disekitarnya, sebaiknya pihak rumah sakit membentuk tim promosi kesehatan agar menambah wawasan pengunjung terhadap bahaya asap rokok serta partisipasi dari lapisan masyarakat sangat dibutuhkan, keamanan maupun petugas kesehatan mengawasi ketertiban dari adanya aturan kawasan tanpa rokok. dan memberikan sanksi jika ada yang melanggar peraturan tersebut, dengan demikian diharapkan dapat mengurangi bahkan menghilangkan konsumsi rokok

\section{UCAPAN TERIMA KASIH}

Terima kasih kepada kedua orang tua dan keluarga yang memberikan seluruh bantuan dan dukungan dalam menyelesaikan penelitian ini.

Terima kasih kepada Fakultas Kesehatan Masyarakat Universitas Al Asyariah Mandar, Kepala Dinas Penanaman Modal dan PTSP, serta Direktur Rumah 
Sakit umum Daerah Kabupaten Polewali

Mandar.

\section{DAFTAR PUSTAKA}

Aditama, T.Y. 2006. Rokok dan Kesehatan. Penerbit Universitas Indonesia Press :Jakarta(WHO, 2008). Data epidemik tembakau di dunia World Health Organization(Riskesdas, 2010).

Habibi, H., Surahmawati, S., \& Sompo, H. (2016). Gambaran Implementasi Peraturan Daerah Tentang Kawasan Tanpa Rokok (KTR) Pada RSUD Haji dan Rumah Sakit Stella Maris di Kota Makassar Tahun 2015. Al-Sihah: The Public Health Science Journal, 8(2).

Mohamad, F., Prabandari, Y. S., \& Priyanto, A. (2012). Peningkatan Pengetahuan dan Sikap Terhadap Bahaya Rokok Bagi Kesehatan Melalui Poster Dengan Partisipasi Siswa di Kabupaten Gorontalo. Berita Kedokteran Masyarakat, 28(1), 29.

Notoatmodjo, S. (2003). Prinsip-prinsip dasar ilmu kesehatan masyarakat. Jakarta: Rineka Cipta, 10.

Rizkia Amalia tahun 2012 Tingkat pengetahuan dan sikap pengunjung di lingkungan RSUP Dr. Karyadi tentang kawasan tanpa rokok.

Sumarwan, U., Jauzi, A., Mulyana, A., Karno, B. N., Mawardi, P. K., \& Nugroho, W.(2011).Riset pemasaran dan konsumen. Panduan Riset Dan Kajian.

StanleyJ.Baran, 2012. Pengantar Komunikasi Massa Jilidl Edisi 5 (Jakarta: PenerbitErlangga) (Sumahandriyani,2015) 